\title{
LA PARTICIPACIÓN DE LOS OFICIOS DE LA CONSTRUCCIÓN EN LAS GERMANíAs de MallorCA
}

\author{
Magdalena Cerdà Garriga* \\ ANTÒNIA JUAN Vicens \\ Universitat de les Illes Balears
}

\begin{abstract}
Resumen
En el presente artículo se analiza el papel ejercido por parte de los oficios de la construcción, a saber, carpinteros y picapedreros, en el conflicto de las Germanías de Mallorca (1521-1523), hito histórico que cierra la Baja Edad Media y que supuso un antes y un después en la evolución político-social de la isla. Los temas a tratar se centran en su grado de implicación en el conflicto, las acciones subversivas perpetradas, así como los cargos detentados durante la contienda. Se incidirá en el modo en que dichos artesanos consagraron sus conocimientos técnicos y sus servicios profesionales a la causa agermanada, con el fin de demostrar la variada actividad constructiva y cómo esta se adaptó a una época de crisis.
\end{abstract}

\section{Palabras clave}

Germanías, Mallorca, conflicto social, carpinteros, picapedreros.

\begin{abstract}
The aim of this paper is to analyse the role played by construction workers, that is to say carpenters and masons, throughout the Germanias (brotherhood) conflict. This revolt took place in Majorca between 1521 and 1523 and it is used as a milestone that ends the Late Middle Ages. It also marked a turning point in the political and social evolution of the island. This article deals with the extent of the involvement of construction workers in the conflict, taking into account the subversive actions they committed, as well as the positions held by them during the revolt. Our work focuses on how these craftsmen dedicated their expertise and professional services to the Germanian cause, in order to demonstrate not only the varied building activity there was, but also how this activity managed to adapt to a time of crisis.
\end{abstract}

\section{Keywords}

Germanias, Majorca, social conflict, carpenters, masons.

\section{Résumé}

Dans cet article est analysé le rôle joué par les métiers du bâtiment, c'est à dire, les charpentiers et les tailleurs de pierres, au sein du conflit des Germanías de Majorque (1521-1523), événement historique qui clôt le Bas Moyen Âge et qui détermine un avant et un après dans l'évolution politique et sociale de l'île. On traitera de l'implication de ces artisans dans la lutte, des actions

* Departament de Ciències Històriques i Teoria de les Arts. Grup de Recerca Estudis Medievals (GRESMED). Universitat de les Illes Balears. Ctra. de Valldemossa, Km 7'5 - 07122 Palma (Illes Balears). Tel. 971172 935. E-mail: m.cerda@uib.es / antonia.juan@uib.es 
subversives qu'ils ont perpétrées, et des charges qu'ils ont exercées pendant le conflit. On insistera sur la façon dont ces artisans ont mis leur expertise et leur activité professionnelle au service des Germanías, à toutes fins de démontrer la diversité de l'activité édificatrice et son adaptation à un moment de crise.

Mots-clés

Germanias, Majorque, conflit social, charpentiers, tailleurs de pierres.

\section{Introducción}

Como es sabido, las Germanías en Mallorca (1521-1523) supusieron un antes y un después en la evolución político-social de la isla, y constituyeron el hito histórico que cerró la Edad Media y dio inicio a la Moderna. Los problemas de base, entre los que se encontraban la Deuda Pública y la tensión Ciudad-Villas, se sumaron a los hechos coyunturales que fueron los que detonaron el estallido del conflicto el Jueves de Carnaval, 7 de febrero de 1521, cuando un grupo de artesanos asaltaron la prisión real reclamando la liberación de siete menestrales activistas que habían sido detenidos por el virrey Miquel de Gurrea el día anterior. A partir de aquí se sucedieron una serie de etapas que evolucionaron desde unos postulados con pretensiones legalistas y de cariz moderado, encarnados por el pelaire Joan Crespí, hasta el radicalismo dictatorial del sombrerero Joanot Colom. La finalización y posterior represión de la revuelta tuvo lugar con la llegada de la escuadra real el 13 de octubre de 1522 y la capitulación de la ciudad el 7 de marzo de $1523^{1}$.

Así pues, atendiendo a su importancia histórica, es lógico que las Germanías supongan un tema que ha gozado de una larga tradición historiográfica. En este sentido cabe remarcar el clásico estudio llevado a cabo por Eulàlia Duran, así como las aportaciones específicas sobre el caso mallorquín tratadas, principalmente, por Álvaro Santamaría, Josep Juan, Miguel Deyá, Margalida Bernat y Onofre Vaquer, entre otros ${ }^{2}$. Estos trabajos se centran en los aspectos político-sociales, económicos e ideológicos del conflicto. Por lo tanto, el estudio de la participación artesana, principal abanderada de la revuelta, se ha analizado desde una óptica general sin prestar especial atención a colectivos

\footnotetext{
Álvaro Santamaría, "Sobre los orígenes de la Germanía de Mallorca”, Mayurqa, 5 (1971), pp. 25-40, Josep JuAn VIDAL, Els agermanats, Ajuntament de Palma, Palma, 1985.

2 Eulàlia Duran, Les Germanies als Països Catalans, Curial, Barcelona, 1982, Álvaro Santamaría, "Sobre los orígenes... pp. 25-40, Josep JuAN VIDAL, "Una aproximación al estudio de las Germanías de Mallorca", Boletín de la Cámara Oficial de Comercio, Industria y Navegación de Palma de Mallorca, 681 (1973), pp. 141-188, Josep Juan Vidal, Els agermanats..., Miguel José Deyá BauZÁ, "Les germanies mallorquines", Història de les Illes Balears. L'època foral i la seva evolució (1230-1715), Erenst Belenguer (dir.), Edicions 62, Barcelona, 2004, vol. 2, pp. 127-138, Margalida Bernat RocA, "Les Germanies", Història de les Illes Balears. L'època foral... pp. 285-313, Margalida Bernat y Jaume Serra, La veu de la revolta. Sermonadors i profetes a les Germanies de Mallorca (1521-1523), Lleonard Muntaner, Palma, 2008, Onofre Vaquer Bennasar, "La repressió dels agermanats", Mayurqa, 26 (2000), pp. $57-71$.
} 
concretos, salvo algunas excepciones ${ }^{3}$. Atendiendo al importante papel ejercido por los gremios a lo largo del conflicto sería preciso un análisis y estudio individual de los mismos para avanzar en el conocimiento y comprensión global de aquel. Por lo tanto, aquí pretendemos profundizar en el papel que en dicha revuelta ejercieron los oficios de la construcción -principalmente carpinteros y picapedreros-, así como las represiones que sufrieron sus integrantes.

Una de las fuentes más importantes e ilustrativas para acercarnos al tema, pese a su sesgo partidista y promonárquico, es Informacions judicials sobre'ls adictes á la germanía en la ciutat é illa de Mallorca, é penas de cos é d'haver á ells imposadas aprés la reducció de 1523 (J. M. Quadrado, 1896-1930). Esta consiste en un listado mandado a realizar por el virrey Miquel de Gurrea entre noviembre de 1523 y marzo de 1524 tanto en la ciudad como en la Part Forana, donde se refleja el nombre, oficio, condición e implicación de los simpatizantes de la revuelta, así como las penas que se les impusieron. A través de la misma, así como de otras fuentes complementarias, se analizarán, aparte de ciertos datos cuantitativos, aspectos como el grado de implicación en la causa agermanada, las acciones violentas que llevaron a cabo, los cargos que detentaron y, especialmente, las funciones y actividades relacionadas con su oficio. Todo ello con una doble finalidad, en primer lugar, aprehender el rol que desempeñaron los oficios de la construcción en la revuelta así como su implicación en la misma. En segundo lugar, averiguar cómo una época de crisis tal como las Germanías repercutió en el seno de dichos gremios.

\section{Datos cuantitativos}

Los oficios de la construcción incluyen, en su mayor parte, carpinteros y picapedreros, quienes formaron gremios independientes en la Mallorca bajomedieval ${ }^{4}$. No obstante,

\footnotetext{
Margalida Bernat Roca, "Algunes notes històriques sobre l'ofici de fusters (Mallorca, segles XIIIXVII)", El moble a Mallorca: segles XIII-XX: estat de la qüestió, Kika Coll (ed.), Consell de Mallorca, Palma, 2011, pp. 24-25. Aunque no se centre en el caso mallorquín, es de citación obligada el estudio de Ricardo García CÁrcel, "Las Germanías de Valencia y la actitud revolucionaria de los gremios", Estudis: Revista de historia moderna, 2 (1973), pp. 97-154.

4 Hecho significativo puesto que no se da en todos los territorios del contexto europeo. Es común encontrar a los diferentes oficios de la construcción aglutinados en el mismo gremio o cofradía durante la Baja Edad Media, dentro y fuera de la Corona de Aragón. Se pueden citar algunos ejemplos como la cofradía de los carpinteros, cuberos, torneros y obreros de villa de Zaragoza (1397); la del Sants Quatre Màrtirs de Gerona, que engloba a los maestros de casas, picapedreros y carpinteros (1419); la de los picapedreros, yeseros y carpinteros de Aix-en-Provence (1450) y la de los maestros de casas, picapedreros, carpinteros de ribera y carpinteros de Cagliari (1473), entre otras. Para más información véanse los siguientes trabajos: Javier IbÁÑEz FernándeZ, "Le corporazioni della costruzione nella Zaragoza del Cinquecento", Le arti del costruire. Corporazioni edili, mestieri e regole nel Mediterraneo aragonese (XV-XVI secolo), Emanuela Garofalo (dir.), Edizioni Caracol, Palermo, 2011, p. 89, Gemma Domènech I Casadevall, Els oficis de la construcció a Girona. 1419-1833. Ofici i confraria. Mestres de cases, picapedreres, fusters $i$ escultors a Girona, Institut d'Estudis Gironins, Girona, 2001, p. 14, Philippe Bernardi, "Statuts inèdits de la confrérie des maçons, plâtriers et charpentiers d'Aix-en-Provence
} 
dentro de cada uno de ellos se englobaron otros oficios afines como los serradores y carpinteros de ribera o los yeseros y canteros, respectivamente. Por ello, se ha optado por estudiarlos en conjunto.

En la fuente antes señalada ha podido constatarse un total de 74 individuos pertenecientes a dichos gremios; 37 vinculados a los oficios que trabajaban con la madera y 37 más de los que obraban la piedra. De ellos únicamente 2 constan como fieles a la monarquía. Por lo que respecta al resto, se cuentan 36 difuntos, de los cuales, 3 fallecieron a causa de la peste ( 2 de ellos en prisión, seguramente en el castillo de Bellver, habilitado para tal fin ${ }^{5}$ ), 3 murieron en batalla en favor de la Germanía, 4 más perecieron reclusos, uno fue sentenciado a la horca y ajusticiado y otro murió a manos de los agermanados. En cuanto a aquellos todavía presentes, el número asciende a 27, 5 de los cuáles se citan como reclusos y 1 de ellos como reo de galeras. También constan algunos ausentes de la isla, 6 en concreto, y en 3 casos no se especifica qué suerte corrieron (tabla 1 y gráfico 1).

Cabe decir que de todos los que figuran en la fuente, tan sólo 5 lo hacen como residentes de la Part Forana, el resto vivía en la capital. Este hecho resulta del todo lógico y comprensible si atendemos a que los iniciadores de la revuelta fueron los gremios de la ciudad, mientras que los habitantes de las villas se sumaron poco después. Recordemos que Ciutat de Mallorques estaba estructurada en cinco parroquias, a saber: Santa Eulàlia y Almudaina, Santa Creu, Sant Jaume, Sant Miquel y Sant Nicolau. Aquella que comprendía una mayor extensión en el seno de la ciudad y, por lo tanto, también la más populosa, era la de Santa Eulàlia/Almudaina donde residían 35 de los efectivos documentados. El resto se repartía entre las demás, especialmente en las de Sant Nicolau (13) y Santa Creu (11), mientras que Sant Miquel y Sant Jaume contaban con un número más reducido, 6 y 2, respectivamente (gráfico 2).

Entre los datos cuantitativos es preceptivo citar aquellos individuos que, tras la finalización de la contienda, se vieron obligados a pagar cierto importe en concepto de multa y/o indemnización por los daños causados (composicions). Puesto que este tema en concreto ha sido ya analizado con detalle por otros autores a partir de una fuente diferente a la aquí estudiada ${ }^{6}$, sólo puntualizaremos que los oficios de la construcción, tras los de la confección textil, fueron los segundos con mayor gravamen ${ }^{7}$.

(1450-1463)", Provence historique, 49/ 195-196 (1999), p. 100, Gabriella Olla Repetto, "L'organizzacione del lavoro a Cagilari tra '400 e '500: La confraternita dei Falegnami”, Sardegna, Mediterraneo e Atlantico tra Medioevo ed età moderna: studi storici in memoria di Alberto Boscolo, Luisa D’Arienzo (a cura di), Bulzoni, Roma, 1993, vol. 1, p. 431.

5 Eulàlia Duran, Les Germanies... p. 334.

$6 \quad$ Llibre de lletres certificatories al procurador reial de les sentencies de confiscacions $i$ composicions de les viles $i$ dels oficis de la Ciutat (Archivo del Reino de Mallorca, AH 4806).

7 Eulàlia Duran, Les Germanies... pp. 355-357, Onofre Vaquer Bennasar, “La repressió... pp. 69-71. 
TABLA 1

Relación nominal de miembros de los oficios de la construcción

\begin{tabular}{|c|c|c|c|}
\hline NOMBRE & OFICIO & FACCIÓN & SUERTE \\
\hline Alós, Jeroni & picapedrero & agermanat & presente \\
\hline Ametler, Joan & yesero & defección & presente \\
\hline Armengol, Antoni & picapedrero & agermanat / mascarat & difunto \\
\hline Artigues, Silvestre & picapedrero & agermanat & presente \\
\hline Ballester, Andreu & carpintero & agermanat & presente (recluso) \\
\hline Barceló, Andreu & picapedrero & agermanat & difunto \\
\hline Barceló, Guillem & picapedrero & agermanat & presente \\
\hline Bauzà-Carrió, Bartomeu & cantero & defección & presente \\
\hline Bertran $(E n)$ & serrador & agermanat & presente \\
\hline Bosch, Miquel & carpintero & agermanat & difunto \\
\hline Canyelles, Antoni & picapedrero & agermanat & difunto (recluso) \\
\hline Català, Guillem & picapedrero & agermanat & presente \\
\hline Català, Jaume & picapedrero & agermanat & difunto (batalla) \\
\hline Catany, Pere & cantero & agermanat & difunto (batalla) \\
\hline Cosme & carpintero & agermanat & no especificado \\
\hline Cucala, Jeroni & carpintero & agermanat & difunto (recluso / peste) \\
\hline Custurer, Bernat & carpintero & agermanat & presente \\
\hline Entens, Joan & picapedrero & agermanat & difunto (ahorcado) \\
\hline Ferrà, Andreu & picapedrero & agermanat & presente (recluso) \\
\hline Ferrer, Miquel & carpintero & agermanat & difunto \\
\hline Font, Antoni & carpintero & agermanat & presente \\
\hline Font, Guillem & carpintero & agermanat & difunto \\
\hline Font, Guillem (vell) & carpintero & agermanat & difunto \\
\hline Francés, Pere & serrador & agermanat & difunto \\
\hline Garau, Antoni & picapedrero & agermanat & difunto \\
\hline Garau, Baptista & picapedrero & agermanat & difunto \\
\hline Garau, Cosme & carpintero & agermanat & presente \\
\hline Garcia, Jeroni & picapedrero & agermanat / mascarat & difunto \\
\hline Gat, Cristòfol & carpintero & agermanat & no especificado \\
\hline Gomis, Miquel & picapedrero & agermanat & difunto \\
\hline Isern, Sebastià & picapedrero & agermanat & difunto \\
\hline Juan, Bartomeu & carpintero & agermanat & presente (recluso) \\
\hline Juan, Llorenç & carpintero & agermanat & presente \\
\hline Juan, Sebastià & picapedrero & agermanat & ausente (desertor) \\
\hline Leó, Bartomeu & picapedrero & agermanat & presente \\
\hline Literas, Joan & $\begin{array}{l}\text { carpintero de } \\
\text { ribera }\end{array}$ & agermanat & presente (cartujo) \\
\hline Llaneras, Antoni & carpintero & agermanat & ausente (desertor) \\
\hline
\end{tabular}




\begin{tabular}{|c|c|c|c|}
\hline Lleonard $(E n)$ & picapedrero & agermanat & difunto \\
\hline Llinàs, Joan & carpintero & agermanat & presente \\
\hline Lopis, Joan & picapedrero & defección & presente \\
\hline Marango, Miquel & $\begin{array}{l}\text { carpintero de } \\
\text { ribera }\end{array}$ & agermanat & $\begin{array}{l}\text { presente (prisión / } \\
\text { galeras) }\end{array}$ \\
\hline Marsà, Lluc & picapedrero & agermanat & difunto \\
\hline Marsal & serrador & agermanat & difunto (recluso) \\
\hline Mestre $(\ldots)$ & carpintero & agermanat & difunto \\
\hline Morro, Antoni & $\begin{array}{l}\text { carpintero de } \\
\text { ribera }\end{array}$ & agermanat & presente \\
\hline Nadal, Pere & serrador & agermanat & difunto \\
\hline Ozona, Miquel & yesero & agermanat & difunto (recluso) \\
\hline Planas, Miquel & carpintero & agermanat & ausente (desertor) \\
\hline Pol, Bartomeu & carpintero & agermanat & difunto (recluso) \\
\hline Pou, Daniel & picapedrero & mascarat & \\
\hline Pou, Sebastià & picapedrero & agermanat & difunto (batalla) \\
\hline Puig, Joanot & carpintero & agermanat & presente \\
\hline Pujol, Pere & picapedrero & agermanat & difunto \\
\hline Ramon, Joan & picapedrero & agermanat & ausente (desertor) \\
\hline Remolar, Pere & carpintero & agermanat & difunto \\
\hline Reure, Bernardí & serrador & agermanat & difunto (recluso / peste) \\
\hline Sagrera, Gabriel & picapedrero & agermanat & presente (recluso) \\
\hline Sagrera, Miquel & picapedrero & defección & presente \\
\hline Salort, Andreu & carpintero & agermanat & difunto \\
\hline Salort, Joanot & carpintero & agermanat & difunto \\
\hline Sans, Pere & carpintero & agermanat & presente (recluso) \\
\hline Santmartí, Gabriel & picapedrero & defección & difunto \\
\hline Sanxo, Pere & $\begin{array}{l}\text { picapedrero/ } \\
\text { yesero }\end{array}$ & mascarat & \\
\hline Sard, Antoni & picapedrero & agermanat & difunto \\
\hline Sard, Joan & carpintero & agermanat & difunto (peste) \\
\hline Sard, Pere & picapedrero & agermanat & difunto \\
\hline Serra, Joan & picapedrero & agermanat & difunto \\
\hline Soldevila, Joan & carpintero & agermanat & no especificado \\
\hline Tarragó, Antoni & $\begin{array}{l}\text { picapedrero/ } \\
\text { yesero }\end{array}$ & agermanat & ausente \\
\hline Tomàs, Miquel & carpintero & agermanat & presente \\
\hline Tremolet, Vicens & carpintero & defección & difunto (agermanats) \\
\hline Vadell, Nadal & carpintero & agermanat & presente \\
\hline Vilasso, Jeroni & carpintero & agermanat & ausente \\
\hline Xemena, Miquel & yesero & agermanat & presente \\
\hline
\end{tabular}

Fuente: Informacions judicials sobre'ls adictes á la germanía en la ciutat é illa de Mallorca, é penas de cos é d'haver á ells imposadas aprés la reducció de 1523 (J. M. Quadrado, 1896-1930). 


\section{GRÁFICO 1}

Distribución de los agermanados de los oficios de la construcción según su situación tras las Germanías (1523)

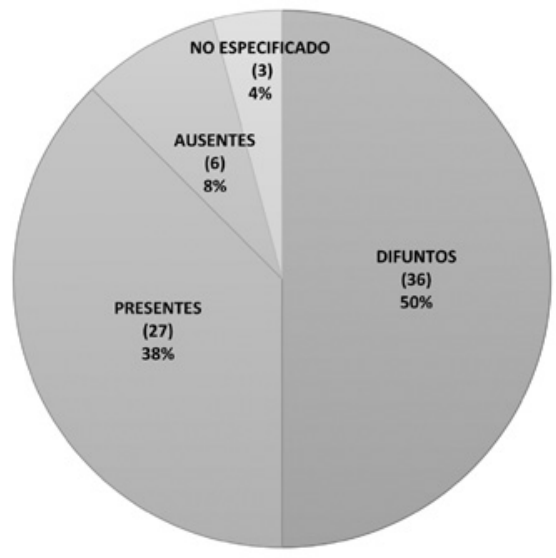

Fuente: Informacions judicials sobre'ls adictes á la germanía en la ciutat é illa de Mallorca, é penas de cos é d'haver á ells imposadas aprés la reducció de 1523 (J. M. Quadrado, 1896-1930).

\section{GRÁFICO 2}

Distribución de los agermanados de los oficios de la construcción por parroquias de la ciudad (1523)

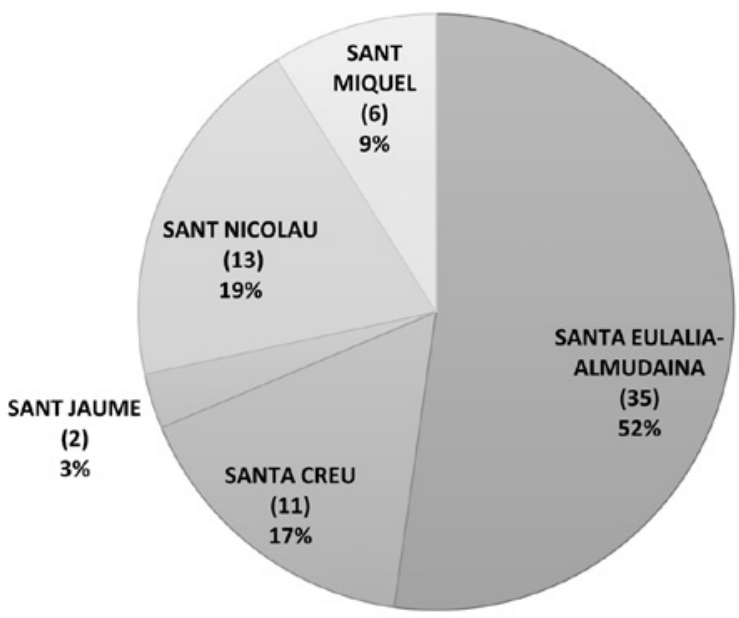

Fuente: Informacions judicials sobre'ls adictes á la germanía en la ciutat é illa de Mallorca, é penas de cos é d'haver á ells imposadas aprés la reducció de 1523 (J. M. Quadrado, 1896-1930). 


\section{Grado de implicación en el conflicto}

El grado de implicación puede medirse en base a dos parámetros, a saber, aquellos que podemos considerar antiagermanados y los proagermanados o instigadores de la revuelta. Deben considerarse aquí también aquellos que gozaron del favor de los líderes de la sublevación.

\subsection{Antiagermanados: Mascarats, desertores y defecciones}

Como se ha comentado previamente, las Germanías fueron un movimiento encabezado sobre todo por miembros de los colegios artesanales. Sin embargo, ello no excluye que algunos de sus integrantes estuviesen en desacuerdo y optasen por apoyar la legalidad vigente encarnada en la figura del virrey. A estos últimos los agermanados les dieron el nombre de mascarats.

Ciertamente, entre los oficios de la construcción no fueron muchos los mascarats documentados como tales desde el principio. De hecho, sólo constan dos individuos: Daniel Pou y Pere Sanxo. En este sentido es muy significativo hacer constar que el hecho de ser o no mascarat era una elección personal que no tenía que ser compartida, necesariamente, por miembros de la misma familia. El caso de los picapedreros Sebastià y Daniel Pou resulta representativo sobre el particular, puesto que de Sebastià se explicita que "ha perseguit mes que tots son germá Daniel qui era mascarat". Del mismo modo, el también picapedrero Gabriel Santmartí repudió a sus hijos por tal motivo: "era inimich de sos fills perque eran mascarats y deya que s'alegraria com los hi aportarien morts" ". Además de los que se acaban de comentar, también encontramos el caso del yesero y picapedrero Pere Sanxo quien fue víctima de y declarante en contra de los agermanados. Víctima porque hay constancia de que fue apaleado por compañeros del mismo gremio quienes, además, le robaron la casa ${ }^{10}$. Visto así, resultaría lógico que declarase como testigo en contra de los agermanados. Sin embargo, en favor de los mismos hay que hacer constar que Sanxo había participado en una conjura para asesinar a Joanot Colom, el líder de la revuelta ${ }^{11}$, intento que resultó fallido pero que sin duda desató la ira de sus seguidores. Entre los partidarios de Colom y aquellos que agredieron a Sanxo se encuentra Gabriel Sagrera, quien fue hermano de Joan Sagrera, antiguo maestro mayor de las obras de la catedral ${ }^{12}$. Por lo que respecta a Pere Sanxo, cabe decir, además, que debía ser afecto al virrey

\footnotetext{
8 Informacions judicials sobre'ls adictes á la germanía en la ciutat é illa de Mallorca, é penas de cos é d'haver á ells imposadas aprés la reducció de 1523, ed. José María Quadrado, Estampa de Felip Guasp, Palma, 1896-1930, p. 16.

(Las citas textuales siguen fidedignamente la transcripción hecha por el autor).

9 Informacions judicials... p. 26

10 Informacions judicials... p. 42 y p. 89.

11 Margalida Bernat y Jaume Serra, La veu de la revolta... p. 80.

12 Antònia JuAn Vicens, Lapiscida vel ymaginarius. L'art de la pedra a Mallorca a la baixa edat mitjana, Publicacions de l'Abadia de Montserrat, Barcelona, 2014, pp. 191 y 219.
} 
Miquel de Gurrea o, al menos, gozar de su confianza. En este sentido, parece ser que resultó electo en los actos de "manipulación" de la elección de los representantes de los oficios, lo que motivó el descontento de muchos agermanados ${ }^{13}$.

$\mathrm{Si}$ bien es cierto que son pocos aquellos que figuran como mascarats desde el principio, no lo es menos que, una vez sofocada la revuelta e iniciada la represión real, se produjeron notables defecciones, incluso entre algunos que fueron en su día acérrimos defensores de la causa agermanada. Es el caso del antes citado Gabriel Santmartí de quien la fuente nos informa que, tras haber desempeñado cargos militares y de haber sido un gran instigador de la revuelta (recordemos que quería ver muertos a sus hijos por ser mascarats), se sometió ("aprés se adobà") 14. Hay otros ejemplos, si bien no tan significativos, como el del yesero Joan Ametler ${ }^{15}$, o los picapedreros Miquel Sagrera, de quien se dice que "no s'agradava de mal"16, y Joan Lopis quien, tras haber luchado con Colom, se redujo y se refugió en la ciudad de Alcudia, reducto fiel al monarca ${ }^{17}$.

Todos los ejemplos citados en el párrafo anterior se produjeron tras la derrota de los agermanados. El abandono de la causa agermanada en pro del bando monárquico antes del nefasto desenlace sólo se ha constatado en la persona de Vicenç Tremolet y de sus hijos $^{18}$, el primero de los cuales, además, murió asesinado a manos de los rebeldes ${ }^{19}$.

Otro caso sería el de los individuos que, durante o después de la sofocación de la revuelta, huyeron de la isla para evitar las posteriores represalias. En esta condición se documenta a los picapedreros Joan Ramon y Sebastià Juan, y a los carpinteros Antoni Llaneras y Miquel Planas ${ }^{20}$. Las argucias para eludir los castigos podían llegar al punto de acudir al amparo de las instituciones eclesiásticas, como por ejemplo Joan Lliteras, carpintero de ribera, quien se hizo cartujo ${ }^{21}$.

A la hora de averiguar el grado real de implicación en el conflicto, resulta difícil hacerlo con aquellos individuos que en la documentación aparecen como muy afectos al mismo y con una actividad representativa, pero que a la vez son tildados de mascarats por algunos testigos. Ello tendría sentido si se tratase de condenados que intentan rehuir las penas impuestas. Sin embargo, los ejemplos de que disponemos, a saber, Jeroni Garcia y Antoni Armengol, figuran como difuntos ${ }^{22}$. Tampoco se trata de una estrategia

\footnotetext{
13 Informacions judicials... p. 77, citado también por Margalida BERNAT y Jaume SERRA, La veu de la revolta... p. 111.

14 Informacions judicials... p. 26.

5 Informacions judicials... p. 6.

6 Informacions judicials... p. 9.

7 Informacions judicials... p. 265.

18 Aunque en la fuente no se especifica su oficio, se trata sin duda del carpintero homónimo documentado como maestro mayor de la catedral en 1522. Joan Rosselló Lliteras, Els pergamins de l'arxiu parroquial de Santa Eulàlia, Consell Insular de Mallorca, Palma, 2000, vol. 3, p. 192; Archivo Capitular de Mallorca, Libro de Fábrica 1775, f. 96.

19 Informacions judicials... p. 6.

20 Informacions judicials... pp. 59, 63, 13 y 86, respectivamente.

21 Informacions judicials... p. 47.

22 Informacions judicials... p. 27.
} 
de los familiares para eludir el pago de las composicions, puesto que todos tuvieron la obligación de abonarlas con independencia de su situación y de su implicación en el conflicto $^{23}$. ¿Podría tratarse de verdaderos infiltrados? Quizá, pero resulta arriesgado realizar tal afirmación sin documentación complementaria más esclarecedora.

\subsection{Sermonadors y avalotadors}

En relación a lo antes expuesto, llaman la atención ciertos individuos, denominados sermonadors que detentaron una interesante actividad arengadora en pro de la sublevación social. Etimológicamente, sermonador se refiere a un orador, a alguien que da un discurso. En este contexto debe entenderse como incitador a la acción, a la lucha social, y como personas comprometidas con la revuelta y sin miedo aparente a la repercusión que su actividad subversiva les podía ocasionar. Es importante tener presente que los agermanados otorgaron a sus actos revolucionarios un cierto carácter profético, mesiánico $\mathrm{y}$ de justicia divina ${ }^{24}$. Al respecto, se puede citar el ejemplo del carpintero Bartomeu Pol del cual se dice que era sermonador y profeta y allegava profecías diabólicas ${ }^{25}$.

Siguiendo a Margalida Bernat y a Jaume Serra, entre las funciones y finalidades del discurso de los sermonadors se contaban tres aspectos. El primero, consistía en una finalidad didáctica, es decir, explicar y crear una opinión. El segundo, implicaba una finalidad coercitiva, a saber, amenazar a sus opositores y a los que no terminaban de estar convencidos, así como reforzar la ideología de aquellos que empezaban a dudar. En tercer lugar, eran los encargados de reproducir oralmente ciertas profecías con la finalidad de reforzar los dos extremos antes citados ${ }^{26}$.

Se ha constatado que en las listas de los adictos a la Germanía aparecen un total de 357 individuos tildados de sermonadors ${ }^{27}$, de los cuales 35 trabajaban en los oficios de la construcción, lo que supone un $9.8 \%$ del total.

Por lo que respecta al término avalotador (alborotador), cabe decir que suele acompañar al de sermonador, puesto que ambas actividades implicaban un acto revulsivo. Además, la fuente suele incidir en que los avalotadors solían ir armados con armas blancas (espadas, puñales, dagas, ballestas) y armas de fuego (espingardas, escopetas) y participaban en la mayoría de mostres y aplechs ${ }^{28}$ que se llevaban a cabo.

\footnotetext{
23 Eulàlia Duran, Les Germanies... p. 349, Onofre Vaquer Bennasar, "La repressió... pp. 59-60.

24 Según han argumentado determinados autores, en última instancia, las Germanías se englobarían en el conjunto de los movimientos heterodoxos de naturaleza religiosa (y social), la mayoría tildados de heréticos, que por aquellas fechas se extendían por Europa (Margalida BERNAT y Jaume SERRA, La veu de la revolta... p. 124, citando a Norman CoHN, En pos del Milenio. Revolucionarios milenaristas y anarquistas místicos en la Edad Media, Alianza, Madrid, 1985).

25 Informacions judicials... p. 86.

26 Margalida Bernat y Jaume Serra, La veu de la revolta... p. 186.

27 Margalida Bernat y Jaume SerRA, La veu de la revolta... p. 186.

28 Mostra se puede definir como una parada y desfile de gente de armas con el fin de examinar, ejercitar o hacer un recuento. Aplech (aplec) hace referencia a una reunión de gente. Fuente: Diccionari CatalàValencià-Balear, Institut d'Estudis Catalans, consulta: 30/07/2014, http://dcvb.iecat.net/.
} 


\subsection{Estatus o consideración entre los líderes de la sublevación}

Recordar aquí que en un primer momento el líder de la revuelta fue Joan Crespí, quien, precisamente por su carácter moderado, fue encarcelado y luego asesinado tras la toma del poder por parte de los hermanos Francesc y Joanot Colom, en especial de este último. Debido a la cronología de la fuente analizada, sólo se refleja el estatus de los artesanos de la construcción en relación a su proximidad o confianza con Joanot Colom.

Como agentes de confianza de Joanot Colom es preciso destacar por su papel de espía e informador al picapedrero Sebastià Isern, quien desde Barcelona se carteaba con él y le transmitía novedades sobre las actividades promonárquicas que allí se estaban llevando a cabo ${ }^{29}$. Por otra parte, Colom tenía también asesores o personas de confianza llamadas consellers o segundos, como los carpinteros Nadal Vadell y Pere Sans o los picapedreros Andreu Barceló y Joan Serra ${ }^{30}$, quienes también destacan por otras acciones violentas que se comentarán en los apartados siguientes. Además, Joanot Colom contaba con una guardia personal integrada por hombres afines a él, quienes lo protegían de atentados - como el más arriba señalado, en el que participó Pere Sanxo- y a quienes pagaba directamente. Entre ellos podemos citar los picapedreros Antoni Garau y Jeroni Garcia, así como el carpintero Bernat Custurer y el serrador Pere Francés ${ }^{31}$.

\section{Acciones violentas}

Cualquier revolución implica actos violentos perpetrados por ambos bandos, no sólo físicos sino también verbales. Sin embargo, atendiendo el sesgo partidista y promonárquico de la fuente analizada, en ella se incide en la maldad y violencia cometidas por los agermanados, sin reflejar aquella incurrida por los vencedores. Además, en este sentido, esta resulta muy gráfica y expresiva. Al respecto, algunas de las testificaciones que se emitieron en contra de los agermanados nos dan a conocer de manera muy elocuente cuáles fueron los agravios y ataques que cometieron. Son ilustrativos algunos de los insultos que proferían y, como hemos visto, se constatan casos de agresión física, por ejemplo los de Pere Sanxo o Vicenç Tremolet. Huelga decir que estos no se limitaban, ni mucho menos, a los mascarats compañeros de oficio, sino que se hacían extensibles a todos los estamentos de la sociedad, en particular a la oligarquía urbana, integrada en su mayoría por nobles, mercaderes e, incluso, notarios.

Los hechos que se consideraron más graves y que por lo tanto se reflejaron más gráficamente en la fuente estudiada tuvieron lugar a lo largo del primer año de la revuelta, 1521. Fueron los asaltos al castillo de Bellver, a la Lonja y al convento de Santo Domin-

29 Informacions judicials... p. 31: "stava en Barcelona y letretjava's molt ab en Colom sobre la germania donantli avis de quant se feya en Barcelona en favor del rey".

30 Informacions judicials... pp. 5, 8-9, 18 y 65 , respectivamente.

31 Informacions judicials... pp. 17, 27, 40-41, 258, respectivamente. Por lo que respecta a Jeroni Garcia y a Bernat Custurer, la fuente no explicita que formasen parte de su guardia personal, sin embargo se puede deducir que efectivamente era así ya que se indica que "anava armat ab en Colom y anava tostemps ab en Colom". 
go. Para este estudio ello resulta significativo puesto que los oficios de la construcción desempeñaron un notable papel en el desarrollo de los mismos.

Cronológicamente, el primer acto a destacar sería el asalto al castillo de Bellver, llevado a cabo el 29 de julio de ese año, lugar donde se refugiaba el antiguo gobernador Pere de Pachs, su familia y algunos caballeros. Entre los miembros de los gremios aquí analizados que participaron en él cabe citar a los carpinteros Jeroni Vilasso, Pere Remolar, Bartomeu Juan y a los picapedreros y yeseros Antoni Tarragó, Antoni Garau, Pere Sard, Andreu Barceló, Joan Serra, Jeroni Alós, Pere Pujol ${ }^{32}$. Como hechos violentos a destacar, se señalan los golpes que Pere Remolar propinó al gobernador Pere de Pachs ${ }^{33}$, así como el ataque directo que el día del asalto al castillo cometió Andreu Barceló sobre la persona del fraile de Alcudia. Este último había acudido a la capital para encabezar una procesión junto al capiscol (chantre) y el canónigo Abrines ${ }^{34}$.

Fue en agosto cuando se produjo un asalto a la Lonja durante una reunión de notarios y mercaderes. La inicial tibieza demostrada por estos colectivos en la participación activa en las Germanías, y su posterior manifiesta hostilidad y negativa de adhesión, condujo a un acto violento contra varios miembros de la oligarquía urbana que se habían reunido en el edificio mercantil ${ }^{35}$. Los carpinteros de ribera tuvieron un destacado papel aquella aciaga jornada al ser ellos los responsables de la destrucción de los accesos al edificio (puertas y rejas). Así, Miquel Marango "lo dia de la Lonja vingué ab una destral para rompre las portas de la Lonja" ", mientras que Antoni Morro "ab una gran destral pegant de grans colps rompé un tros de retxat de Lonja para matar los qui eran dins en favor del rey" 37 .

En relación al último acto violento a remarcar, primero debe hacerse hincapié sobre el papel ejercido por las órdenes mendicantes. Parece ser que los franciscanos fueron proagermanados, puesto que en su recinto tuvieron lugar algunas de sus asambleas revolucionarias. Por otra parte, los dominicos se decantaron por el bando contrario ${ }^{38}$. Por ello se entiende que su convento no sólo fuese refugio de mascarats sino también custodio de sus pertenencias y objetos de más valor ${ }^{39}$. Algunos llegaron incluso a encerrarse allí para eludir la amenaza externa. A ello se debió que el último de los asaltos a qué nos hemos referido tuviese lugar, precisamente, en dicho convento el día 1 de noviembre de 1521. Este fue motivado por el descontento que suscitó el sermón de un fraile dominico entre los agermanados. Ello conllevó el allanamiento del recinto sagrado y la subsiguiente localización del escondrijo donde se habían escondido un grupo de mascarats. Fue el picapedrero Antoni Armengol, alias Cap de Ferro, quien lo descubrió y quien, junto al

32 Informacions judicials... pp. 13, 81, 88, 13, 17, 18, 65 y 72, respectivamente.

33 Informacions judicials... p. 81. En este sentido cabe tener presente que Pere de Pachs no había sido nombrado gobernador por el monarca sino por los mismos agermanados.

34 Informacions judicials... p. 18.

35 Eulàlia Duran, Les Germanies... pp. 294-295, Josep Juan VidaL, Els agermanats... p. 74.

36 Informacions judicials... p. 47.

Informacions judicials... p. 49.

Margalida Bernat y Jaume Serra, La veu de la revolta... p. 82.

Josep JuAn VIDAL, Els agermanats... p. 73. 
también picapedrero Baptista Garau, lo demoliót ${ }^{40}$. Tras ello se produjo el asesinato de una docena de personas en cuyos cadáveres se ensañó el carpintero Nadal Vadell ${ }^{41}$.

Al margen de estos tres actos tan señalados y remarcados por la fuente en cuestión, también se precisa subrayar que la mayoría de los adictos son tildados de ladrones, asesinos, violadores ("gran desonestador de dones") ${ }^{42}$, instigadores del mal y otras lindezas. De todas ellas, quizás la más significativa sea la de matadors. Esta, si se analizan en detalle las observaciones emitidas en la fuente, no parece ser que haga referencia sólo a asesinos en sentido general, sino más bien a la existencia de una especie de facción armada, la más radical de la Germanía, encabezada por Francesc Colom. Ello se desprende de algunos comentarios, como por ejemplo aquél que hace referencia al serrador Pere Francés de quien se dice que formaba parte de "la guarda den Colom" y que "anava ab lo dit Francesch Colom y ab los matadors" "3.

\section{Cargos}

Entre los muchos cargos detentados por miembros de los gremios objeto de estudio, puede hacerse una división entre aquellos de carácter militar y otros de distinta naturaleza.

\subsection{Cargos militares}

Básicamente se contemplan dos categorías militares: cinquantaner y desener ${ }^{44}$. Ambas eran dos tipos de organización de una fuerza militar que ya había demostrado su efectividad en la campaña de Bugía (1515) ${ }^{45}$. Así, este sistema de distribución de hombres armados proviene de las órdenes de leva de la tropas de Bugía en la que participaron los gremios mallorquines, estructurados en colegios artesanales ${ }^{46}$, entre los que, obviamente, aparecen picapedreros y carpinteros. Su aplicación material a las Germanías se produjo durante el período dictatorial de Joanot Colom, tras ser anulada la Tretzena o consejo de los trece, en vigor durante la etapa de Joan Crespíi ${ }^{47}$. Los cinquantaners formaban una compañía de cincuenta hombres de la milicia de los agermanados y tenían bajo sus órdenes a cinco deseners. En ocasiones no queda del

\footnotetext{
40 Informacions judicials... pp. 18 y 27.

41 Este "lo dia que mataren los mascarats de St. Domingo ell hi aná y ab la crossa que aportava los pegà de crossades y bastonades aprés que'ls hagueren morts” (Informacions judicials... p. 5).

42 Informacions judicials... p. 17.

43 Informacions judicials... p. 23.

44 Los cargos militares de cinquantaner y desener ya aparecen en el contexto catalán a finales del siglo XIV, concretamente en el censo militar de la ciudad de Barcelona del año 1389. Vid. Francisco Marsà, Onomástica barcelonesa del siglo XIV, Universidad de Barcelona, Barcelona, 1977, p. 19.

45 Francisco Sevillano, "Mallorca y la defensa de Bugía, 1515", Bolletí de la Societat Arqueològica Lul·liana, 33 (1971), pp. 332-370.

46 Margalida Bernat y Jaume Serra, La veu de la revolta... p. 44.

47 Margalida Bernat y Jaume Serra, La veu de la revolta... p. 45, Eulàlia Duran, Les Germanies..., pp. 289-293.
} 
todo claro en la documentación de la época la diferencia entre cinquantaner y capitán. Entre sus funciones se encontraba llevar a cabo el registro de la isla y confiscar las armas de fuego que se localizasen ${ }^{48}$. Además, el cargo confería al que lo ostentaba la posibilidad de ocupar otros también revestidos de cierta responsabilidad e importancia, no necesariamente de naturaleza militar, tal y como se explica más adelante. Se ha podido constatar un total de ocho cinquantaners, entre los cuales destacan el picapedrero Gabriel Santmartí y el carpintero Miquel Bosch. El primero ya había ostentado el mismo cargo en la campaña de Bugía, mientras que el segundo ocupó el de desener ${ }^{49}$. Por su parte, cada desener tenía a su cargo nueve hombres de la milicia de los agermanados y, a su vez, estaban bajo las órdenes de los cinquantaners. Podría decirse que era el primer escalafón en la jerarquía social y militar agermanada. Pese a su relevancia, esta no fue tanta como la conferida a los primeros. Entre los documentados han podido constatarse cuatro pertenecientes a los oficios de la construcción.

\subsection{Otros cargos}

Entre otros cargos a destacar se contemplan los de repartidor del pan (partidor del pa), sobreposat o mayordomo del oficio, morbero, carcelero $^{50}$, tasador y guardián.

Uno de los más representativos es el de repartidor de pan, tal y como lo demuestra el hecho que algunos cinquantaners desempeñasen a la vez este cargo ${ }^{51}$. Téngase en cuenta la importancia de la distribución de los alimentos, especialmente durante el asedio de las plazas. Un dato significativo y a tener en cuenta es aquel que nos informa sobre el monopolio y la parcialidad con la que el pan era distribuido, únicamente entre los agermanados, hecho que podía acarrear agravios físicos entre quienes detentaban el cargo. $\mathrm{Al}$ respecto, el carpintero Miquel Bosch "partia lo pa per la germania de manament den Colom y no'n donava sino als agermantas, y per lo partir del pa li pegaren una coltellada en la ma y tallaren li dos dits" ${ }^{52}$.

Otros cargos compaginados, también, por algunos cinquantaners eran los de morbero, tasador y/o composador o guardián ${ }^{53}$. El primero era el responsable de salvaguardar la sanidad pública para intentar evitar la propagación de epidemias. Los segundos se relacionan con cuestiones de carácter fiscal como la recaudación de tributos.

\footnotetext{
48 Margalida Bernat y Jaume Serra, La veu de la revolta... p. 105.

49 Francisco sevillano, "Mallorca y la defensa... pp. 356 y 358, Informacions judicials... pp. 21 y 26.

50 Tan sólo contamos con un ejemplo documentado como carcelero de la prisión de la ciudad, el carpintero Miquel Tomás (Informacions judicials... p. 26).

51 Informacions judicials... pp. 12 y 21.

52 Informacions judicials... p. 21.

53 Los ejemplos más destacados son el del picapedrero Jeroni Alòs, que reunió los cargos de cinquantaner, composador y morbero (Informacions judicials... p. 65); el del yesero Miquel Ozona, quien fue cinquantaner, composador y tasador (Informacions judicials... pp. 84-85) y el del serrador Bernardí Reure, que fue cinquantaner y guardián de la parroquia de Santa Cruz (Informacions judicials... pp. 48-49).
} 
Aquellos que aparecen en mayor número son los que realizan funciones de guardia. Entre ellas, la más frecuente es la custodia de sistemas defensivos de la ciudad (murallas y puertas de acceso), aunque también se ha localizado un ejemplo de guardián de una parroquia, entendida esta como distrito de la ciudad ${ }^{54}$. La organización de la defensa de las murallas iba a cargo de los artesanos, quienes formaban una milicia para tal fin y se estructuraban para la defensa en tramos de la misma. Parece ser que ello tiene sus orígenes en el primer cuarto del siglo XV, pero que no se consolidó hasta principios del XVI ${ }^{55}$. Ello se refleja en las Germanías cuando muchos de los agermanados, miembros de los oficios de la construcción, aparecen en las fuentes como guardianes de algunas de las puertas de la muralla. Resulta lógico que picapedreros y carpinteros estén relacionados estrechamente con la guarda y custodia de murallas y puertas. Ello es debido a la importancia defensiva de estos elementos y al papel ejercido por dichos oficios en su mantenimiento y reparación, tal y como se analizará en el siguiente apartado. Así pues, de los seis custodios de puertas y murallas, los tres picapedreros documentados lo son de las puertas de Santa Catalina y de Sant Miquel ${ }^{56}$, en cambio los tres carpinteros lo eran de la muralla ${ }^{57}$.

Finalmente, es preciso señalar el cargo más estrechamente relacionado con la jerarquía gremial. Nos referimos al de mayordomo (sobreposat o cap d'ofici), de elección anual y supuestamente reservado a aquellos maestros, en cierto modo, ya consolidados. Aunque el sistema de elección se regía por el llamando sort e sach (insaculación), cabe decir que en un determinado momento dicho sistema adoleció de "manipulaciones" externas, tanto por parte del bando agermanado como por las autoridades legales, con la pretensión de que los electos fueran afines a sus ideales (recordemos el ejemplo antes citado de Pere Sanxo). En el caso particular del gremio de los picapedreros, los mayordomos agermanados fueron Gabriel Santmartí y Miquel Sagrera, este último electo por el mismo Joanot Colom, hecho ilustrativo de lo antes expuesto ${ }^{58}$.

\section{Funciones y actividades relacionadas con su oficio}

Un aspecto más interesante, si cabe, que los enunciados anteriormente, es el modo en que dichos artesanos consagraron sus conocimientos técnicos y sus servicios profesionales a la causa agermanada. Ello demuestra la variedad de la actividad constructiva y su adaptación a una época de crisis. Al respecto, las actividades generales que llevaron a cabo pueden ser agrupadas en cinco tipos:

- Desempeño de cargos relacionados con el oficio como maestro mayor de las murallas o maestro mayor de la ciudad.

54 Vid. nota 53.

55 Margalida Bernat y Jaume SeRra, La veu de la revolta... p. 102.

56 Miquel Sagrera jove y Gabriel Sagrera custodiaban la primera, mientras que Pere Pujol vigilaba la segunda (Informacions judicials... pp. 9, 89 y 72, respectivamente).

57 Miquel Ferrer, Cosme Garau y Miquel Planas (Informacions judicials... pp. 74, 83 y 86, respectivamente).

58 Informacions judicials... pp. 26 y 9, respectivamente. 
- Reparación de sistemas defensivos.

- Fabricación de maquinaria de asalto y munición.

- Provisión de material.

- Destrucción de patrimonio de los mascarats.

En relación a la ostentación de puestos de cierta notabilidad, son cuatro los maestros que se han podido documentar. Tal vez uno de los más interesantes sea el ejemplo de Baptista Garau quien "tenia l'offici de mestre de la ciutat per la germania, y adobava las muradas y las ayguas" "59. Según se desprende de esta cita, parece ser que fue la propia Germanía o, mejor dicho, la cúpula dirigente de la misma quien le nombró como tal. Sin embargo, a través de documentación complementaria sabemos que la elección de Baptista Garau fue a cargo de los jurats el mes de julio de 1521, quienes lo designaron en el puesto en sustitución del antiguo maestro mayor, Macià Nonell o Novell, debido a que este último "stà malat, és home ja vell e no hi veu" 60 . Pese a ello, debe tenerse en cuenta que en el mes de julio de 1521 el poder fáctico residía ya en los agermanados, mientras que el papel político de las estructuras de gobierno de la ciudad era nominal. Además del antes citado, encontramos a otros tres maestros que desempeñan la función de maestros mayores de la muralla. Uno de ellos es el picapedrero Antoni Armengol, denominado "capitá de adobar totas las muradas per en Colom" "61. Los otros dos son el carpintero Bernat Custurer y el picapedrero Bartomeu Leó ${ }^{62}$, de quien se dice que "tostemps anava adobant y tapant forats molt diligent". A través de ello se refleja la importancia de mantener en condiciones el principal elemento defensivo de la ciudad y, por lo tanto, de ello se deduce la relevancia intrínseca del cargo desempeñado por dichos artesanos.

Por otro lado se documenta la reconstrucción de elementos clave en el ámbito defensivo, como la de las puertas de fortalezas -en este caso concreto las del castillo de Bellver-, ejecutadas por el carpintero Andreu Salort, miembro destacado de una importante saga de maestros mayores de la catedral a lo largo del siglo XV y de principios del XVI ${ }^{63}$, y

\footnotetext{
59 Informacions judicials... p. 18.

60 ARM, Extraordinaris Universitat 29, f. 393, vid. Antònia JuAn Vicens, "La figura del Maestro de las obras de la ciudad, de una Urbs medieval: el caso de Mallorca", Construir la ciudad en la Edad Media, Beatriz Arízaga Bolumburu y Jesús Á. Solórzano Telechea (ed.), Instituto de Estudios Riojanos, Logroño, 2010 , p. 367 , nota 41.

${ }^{61}$ Informacions judicials... p. 27. El título de capitán no implica necesariamente un carácter militar, sino que en muchos casos se utilizó como un símbolo de prestigio por parte de los agermanados (Margalida BERNAT y Jaume SERRA, La veu de la revolta... p. 104).

62 Informacions judicials... pp. 40-41 y 72 , respectivamente.

63 La saga de los carpinteros Salort como maestros mayores de la catedral abarcó ocho décadas. Las tres generaciones consecutivas fueron: Joan Salort (1445-1460), Martí Salort (1468-1480) y Andreu Salort (14841521). ACM, Libros de Fábrica 1730-1774. El papel de Andreu Salort en el seno del gremio también es notable, ya que fue sobreposat del mismo en 1514 (ARM, Protocolo S-1068, f.s) y prohom el año siguiente (ARM, Protocolo S-1069, f. 13). Asimismo, en 1499 ya había ocupado el cargo de conseller dels menestrals en el Gran i General Consell (ARM, Extracció Oficis 23, f. 95-95v).
} 
quien, desafortunadamente, falleció antes de que pudiese finalizar el encargo ${ }^{64}$. Recordemos que Bellver había sido asaltado por los agermanados en julio de 1521, a consecuencia de ello las puertas fueron quemadas, hecho que originó la necesidad de su reconstrucción.

En el asedio de la ciudad promonárquica de Alcudia fue realmente necesaria la participación de los carpinteros como constructores de máquinas de guerra, entre las que se contaban tortugas ${ }^{65} \mathrm{y}$ otros ingenios como andariveles ${ }^{66}$ y escaleras de asalto ${ }^{67}$. Son tres los artífices que se han podido documentar participando en la construcción de dichos ingenios. Uno de ellos es Bartomeu Pol -artista conocido por su diversificada producción ${ }^{68}$ y que falleció durante su reclusión en la ciudad por la causa agermanada- quien "aná a Alcudia en favor den Colom y feu las scalas para pujar a la murada y un enginy para prendre la vila" "69. Los otros dos son Bartomeu Juan y Nadal Vadell. De este último se especifica que "aná contra Alcudia per fer lo endirivell y tortuga y scalas per combatre y altras fabricas que ell prometia fer per pendre Alcudia" "70. Por lo que respecta al apoyo a la infraestructura bélica, en él se debe también incluir la fabricación de armas y munición. Así, el carpintero Guillem Font confeccionaba trompas de foch para lanzar fuego dentro de la ciudad asediada de Alcudia $^{71}$ y el picapedrero Lluc Marsà fabricaba proyectiles ${ }^{72}$.

Ya como últimos puntos a destacar, citemos el suministro de material y la destrucción de patrimonio, en muchas ocasiones con vistas a la provisión del mismo. Este solía

64 Informacions judicials... p. 44.

65 Máquina de guerra móvil proveída de una cubierta bajo la cual se abrigaban los soldados al acercarse a una fortaleza asediada. Fuente: Diccionari Català-Valencià-Balear, Institut d'Estudis Catalans, consulta: 30/07/2014, http://dcvb.iecat.net/.

66 Mecanismo usado para pasar ríos y hondonadas que no tienen puente, consistente en una especie de cesta o cajón, comúnmente de cuero, que, pendiente de dos argollas, corre por una maroma fija por sus dos extremos. Fuente: Diccionario de la Real Academia de la Lengua Española, Real Academia Española, consulta: 30/07/2014, http://www.rae.es/.

67 Este aspecto también fue señalado en su día por Margalida BERnAT RocA, "Algunes notes històriques... pp. 24-25.

68 El carpintero Bartomeu Pol llevó a cabo importantes encargos, algunos para la catedral de Mallorca. Entre ellos se ha documentado la factura de dos imágenes devocionales - una de San Juan Evangelista y otra de Cristo resucitado- en 1512, la confección de planchas para estampas devocionales (1513), el encargo de un retablo dedicado a San Miguel junto con el pintor Bartolomé Martínez (1516) y también se sabe que trabajó en la renovación del coro catedralicio a inicios del siglo XVI. Vid. Gabriel Llompart y Joana Maria Palou, "De portal a portal: innovació i tradició a l'escultura mallorquina del segle XV", Al tombant de l'edat mitjana: tradició medieval i cultura humanista, Maria Barceló Crespí (coord.), Institut d'Estudis Baleàrics, Palma, 2000, p. 424, Gabriel LlaBRÉS "Los estampadores en Mallorca”, Bolletí de la Societat Arqueològica Lul·liana, 19 (1922-1923), pp. 343-345, Juan MunTANer BujosA, "Para la historia de las Bellas Artes en Mallorca", Bolletí de la Societat Arqueològica Lul-liana, 32 (1961-1967), p. 566, Gabriel Llompart y Joana Maria PALOU y Isabel Mateo, "El cor", La Seu de Mallorca, Aina Pascual (coord.), Olañeta, Palma, 1995, pp. 108-109.

69 Informacions judicials... p. 86.

70 Informacions judicials... pp. 88 y 5 , respectivamente.

Pese a que Antoni Mas defiende que la construcción de las tortugas fue llevada a cabo por comuneros castellanos, en la fuente aquí analizada se explicita que sus ejecutores fueron artífices mallorquines (Miquel Josep Deyà BauzÀ, Antoni Mas Forners, Ramon Rosselló Vaquer, Història d'Alcúdia. El segle XVI, Ajuntament d'Alcúdia, 1999, pp. 24-25).

71 Informacions judicials... p. 20.

72 Concretamente "feya pedra de bombardas" (Informacions judicials... p. 21). 
comprender básicamente madera (lenya) que casi siempre se destinaba a la reparación de elementos defensivos ${ }^{73}$. Entre sus principales proveedores se encuentran el ya mencionado Bernat Custurer, Miquel Tomàs y Llorenç Juan, alias Parbó. Cabe decir que el principal medio era el robo y expolio de propiedades de mascarats $^{74}$. En este mismo sentido y a requerimiento del líder Joanot Colom, Gabriel Sagrera se encargaba de destruir viviendas, de las cuales, es de suponer, reutilizaban el material expoliado ${ }^{75}$.

\section{A modo de conclusión}

En definitiva, se puede concluir que el grado de implicación de los oficios de la construcción en el conflicto de las Germanías de Mallorca fue notable. Al respecto, resulta revelador el activismo de ciertos miembros de familias de artesanos que habían consolidado su prestigio en la profesión a lo largo del siglo XV, como la de los Salort y la de los Sagrera.

Al servicio de la revuelta pusieron no sólo la vehemencia y el anhelo necesarios para cambiar una realidad que creían injusta sino también su conocimiento técnico y habilidad en la práctica del oficio. Así se ha comprobado con los ejemplos de los sermonadors y con la de aquéllos que participaron en el mantenimiento y reparación de los sistemas defensivos y en la factura de ingenios mecánicos.

Con todo, el fracaso de le empresa conllevó consecuencias, en cierto modo, no muy positivas para el posterior desarrollo de la actividad constructiva en la isla. En este sentido, el desenlace del conflicto supuso la desaparición de algunos de los maestros más preeminentes de las últimas décadas de la Edad Media. Al respecto, se puede recordar como el fallecimiento de Andreu Salort y el de su hijo Joanot conllevó la sustitución de esta saga de carpinteros en la dirección de la maestría de la catedral por la de los Tremolet, estos últimos favorables al rey durante la Germanías. También, la muerte de Joan Serra y de Antoni Armengol implicó la desaparición de dos importantes maestros, miembros de algunos de los talleres de artesanos de la piedra más prestigiosos de finales de la época medieval. Finalmente, también se debe citar que las Germanías supusieron la desaparición de uno de los artistas de la madera más prolíficos y versátiles de inicios del siglo XVI, Bartomeu Pol, especializado en obra sacra. Estas pérdidas coinciden y subrayan el papel de las Germanías como punto de inflexión entre la Edad Media y la Época Moderna.

Fecha de recepción: 28 de noviembre de 2014

Fecha de aceptación: 5 de marzo de 2015

\footnotetext{
73 Llorenç Johan, alias "Parbó, prenia lenya de casa dels mascarats per adobar la murada" (Informacions judicials... p. 12).

74 Bernat Custurer "enderrocava casas y orts per furtar lenya" (Informacions judicials... pp. 40-41).

75 Informacions judicials... p. 89.
} 